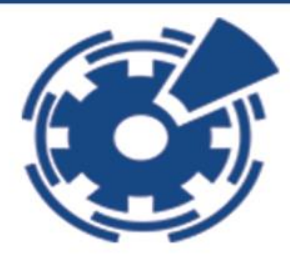

26-28 July, 2019 London, United Kingdom

\title{
Analysis on Club Head Velocity versus Golf Handicap in Greenside Bunker
}

\author{
Josefa Wivou¹, Pubudu N. Pathirana², Van T. Huynh3 and Lanka Udawatta4* \\ ${ }^{1,2,3}$ School of Engineering, Deakin University, Melbourne, Australia \\ ${ }^{4}$ Department of Mechatronics Engineering, Higher Colleges of Technology, UAE
}

\begin{abstract}
The purpose of this research study is to investigate the relationship between club head speed and golf handicap in relation to greenside bunkers. Biokin-Mobi sensor setup designed to capture three dimensional movement patterns of club head movements is employed in order to gather real time golf swing data. The angular velocity records captured during the greenside bunker shots are examined and correlated with handicaps of both skilled and amateur golfers. There is a significant difference between the club head speed of an elite and club head speed of an amateur golfers when executing greenside bunker shots. In particular, by examining peak velocities of the back and down swings, this study shows that club head speeds are valid indicators of golfers' performance measures.
\end{abstract}

Keywords: Club head speed; handicap; angular velocity; sensing; sand bunkers

\section{Introduction}

Golf is a relaxing and sociable game considered by many and played by more than 60 million players around the world ("The truth about Golf", 2018). It is a non-contact game that can be taken up and played by the young, old, male and female (Farrally, 2003). Player's skill levels are gauged and monitored by a universal handicap system that allows players of all levels to compete fairly in both local and global competitions. However, at professional competitions, handicaps are not considered as players have gained professional status through recognized institutions and training centres to enable participation at the highest level ("European Golf Association Report", 2019). Handicaps (skill levels) range from 0-28 for male and 0-36 for female. The lower the handicap signifies better skilled players while higher handicap indicates less skilled players, hence at professional level handicap is considered to be zero or below (Betzler, 2008).

Golf courses are specifically designed to be challenging with sand traps known as bunkers (depression with varied depth filled with selected sand) which are strategically placed in the 


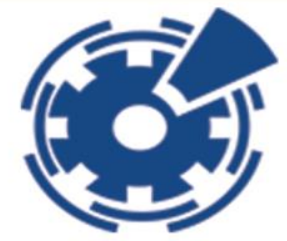

fairway and around the putting greens. Putting greens are at the end of each hole with very fine cut grass where the ball is finally holed. Most golf courses around the world are commonly designed to have 18 holes (4x3 par three holes, 10x4 par four holes and 4x5 par five holes) with varied lengths depending on the 'tee box' setup for professionals (black), amateurs (green or blue), seniors (white) and ladies (red). Greenside bunkers shots are considered to be one of the most challenging shot in a round of golf by many players at all levels even with the professionals (Brown, 2011).

This is the only shot in golf where the club head is not in direct contact at impact with the ball but the club head enters the sand few centimetres behind the ball splashing the sand and the ball forward towards the intended target as shown in Figure 1(a) and 1(c). The swing length and club head speed depend on the distance intended for the ball to be projected to be as close as possible to the hole if not ideally in (Bradshaw, 2009). However, in fairway bunkers the ball is struck similar to a regular golf shot aiming to gain maximum distance while on the fairway. On the other hand, in the greenside bunkers, if the shot is not executed effectively, it could destroy the players score card and regrettably the day as well for both regular golfers and professionals. Limited scientific research studies have been done on the professionals that so often execute remarkable and effective greenside bunker shots that makes the difference in the score card and their earnings. This has prompted the current study to investigate and identify significant features that are inherent in the skilled golfers' biomechanics motion that contributes towards an effective greenside bunker shot which can be used for training and performance enhancement purposes in lesser skilled golfers.

Figure 1: (a) Bunker shot setup, (b) Ball to rest within $1 \mathrm{~m}$ circumference of the pin, (c) Club head entry into the sand few centimetres behind the ball

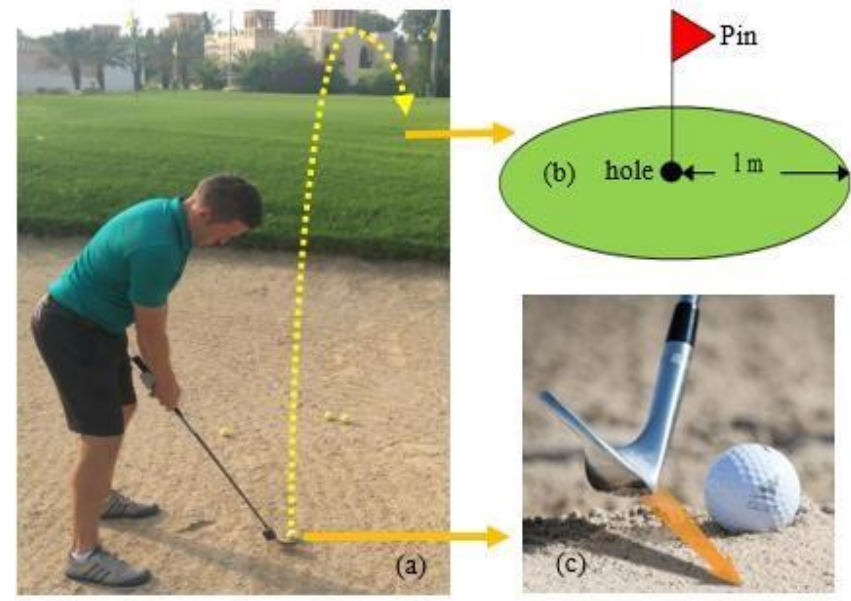




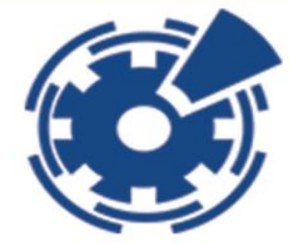

For the purpose of this study, an effective greenside bunker shot is considered to be when the ball is at rest within one-meter circumference of the pin (hole) on the putting green surface after the shot is taken. Figure 1(b) shows a visualization of an effective greenside bunker shot which is considered very puttable by most players (Smith, 2008). An effective greenside bunker shot is executed more regularly by the skilled lower handicap players than the lesser skilled high handicap players. Single figure handicap players have acquired strength in all areas of the game that makes them a better player than the higher handicap players which may have limited strength in certain areas of the game. Earlier studies have identified that club head speed at impact during the execution of a golf shot swing is a significant parameter for a good professional golf shot (Wang, 2015) and (Grober, 2010). It is found that high handicap players have lower club head speeds at impact which contribute to the lesser effective shots (Fradkin, 2005) and (Joyce, 2016). Correct timing of the shoulder turn and torso in the swing for the release of the club head at impact contributes to the club head speed (Choi, 2016). The remaining part of this research paper is organized as follows. In Section II, golf swing dynamics and related details of the variables are presented. Data capturing with the BioKin sensor system is explained in Section III. Analysis and results obtained through the experiments are presented in Section IV. Finally, concluding remarks are given in Section $\mathrm{V}$.

\section{Golf Swing Dynamics}

The dynamics of the golf swing is very important to every golfer. Nonetheless, players normally spend hours on the practice range (see Figure 2) in an attempt to find the perfect golf swing which suits to that particular individual. Golf swings come in all shapes and sizes with different components combined to produce a perfect swing. There are four phases to a golf swing [16], however it can be combined to the two main phases that are:

- The backswing - a coordinated backward movement of the golf club with a rotation of the trunk of the golfer.

- The downswing - the club head is moving at maximum speed when arriving at the impact point.

To have an effective golf shot or golf swing, energy associated with the strike is very important. In fact, the golf club acquires its energy from three sources. First, torque produced by the arms of the player as they move through the arc of the downswing is the main energy source which can be controlled by the player. Second, the potential energy of the arms and club which turns to kinetic energy as the arms and club drop down during the downswing will enhance the impact force. The work done by the golfer during the weight shifting of the axis of the swing is the third component. In this study, we focus on a particular swing which is called a "Greenside Bunker Shot". This shot is necessary to execute when the golf ball rests in a sand bunker. When executing 


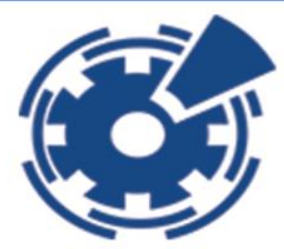

26-28 July, 2019 London, United Kingdom

an effective greenside bunker shot, the club is sliding underneath the ball using the bounce of the wedge, moving fast and skipping through the sand together with the ball. In order to have proper bunker shot, the clubface needs to be open somewhat in relation to the target.

Figure 2: A typical practice range in a golf course

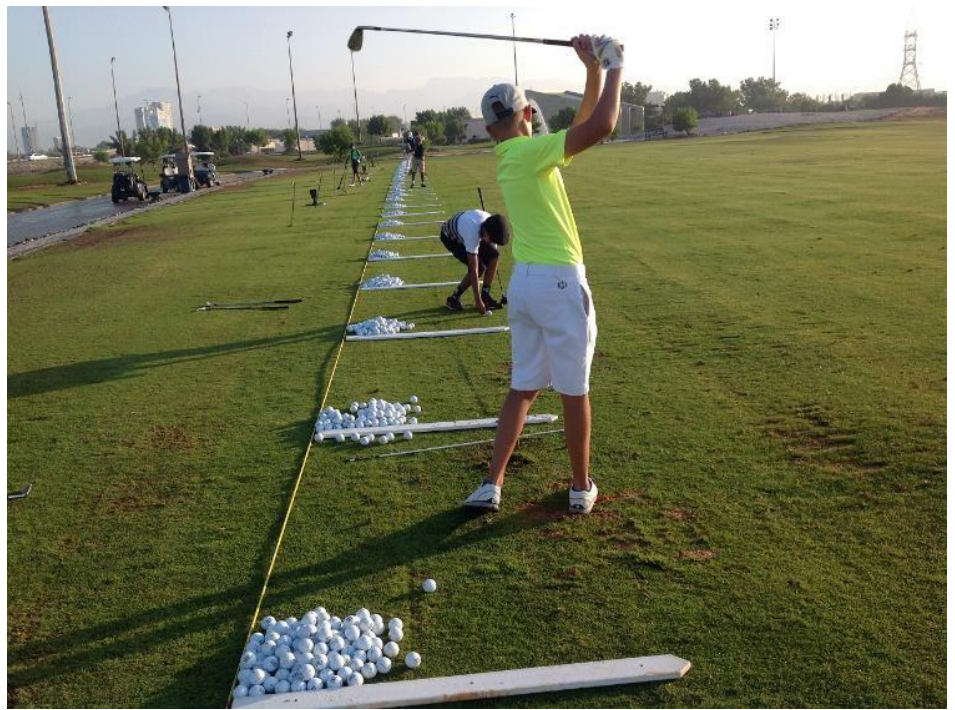

Let us consider the distance (D) from the golf ball position to the pin or nearest to the pin along the $\mathrm{x}$-direction given by $D \square f\left(x_{1}, x_{2}, x_{3}, \ldots, x_{n}\right)$. For a given distance or desired distance, from the ball position to the pin location, different parameters should be optimally combined and swing should be executed. The distance $D$ can be seen from the ball placement in the sand to the pin position in the experimental setup. The swing shown in Figure 2 can be approximated to a circular path of the wrist. Figure 3 illustrates the circular path of the wrist a golf club. Here, $r$ is the radius of the golfer's swing path and $\mathrm{G}$ is the centre of mass of the golf club. The length shown in the diagram IG is the distance from wrist to the centre of mass of the golf club. Whereas is the swing angle the golfer's arms made with the vertical direction and is the angle the golf club made with the golfer's arms.

With the above mentioned parameters, a general position of $\mathrm{G}(x, y)$ is the position of the center of gravity of the club. It can be expressed as

$$
(x, y) \equiv(-r \sin \theta+l G \sin (\theta+\alpha), r \cos \theta-l G \cos (\theta+\alpha)) .
$$

Force exerted on the ball in the $x$-direction $F_{x}$, can be expressed in combination with the moment created by the wrist on the club $M_{w}$ as follows:

$$
M w-F x l G \cos (\theta+\alpha)-F y^{\prime} l G \sin (\theta+\alpha)=I G(\alpha c l u b) .
$$

Finally, the club head velocity can be shown as, 


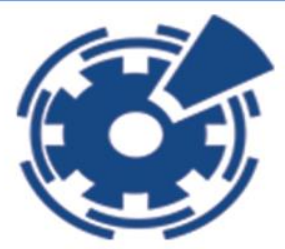

26-28 July, 2019 London, United Kingdom

$$
v=-r \theta \cos \theta+l_{\text {club }}(\theta+\dot{\alpha}) \cos (\theta+\alpha) .
$$

Here, the $l_{c l u b}$ is the length of the gold iron or club used for the shot.

Figure 3: Approximated circular path of the wrist

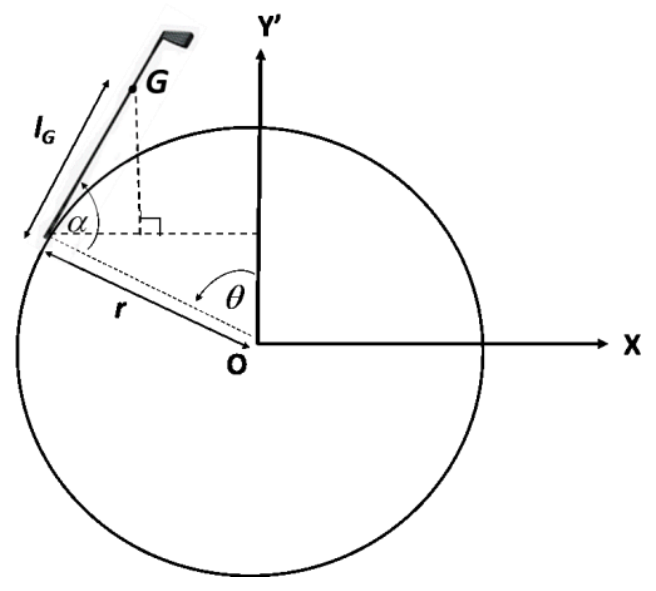

\section{Data Capturing System}

In these experiments, we use BioKin-Mobi sensor setup to capture golf swing motion. In particular, the velocity of the golf club head (v) which is one of the key important parameters is recorded. The 9-axis inertial measurement units (IMUs), here namely, Biokin sensor platforms have been used to record three measurement vectors from accelerometer, magnetometer and gyroscope. To analyse a given condition, it is essential to have accurate data from the golfer including swing of the arms, wrist and the club systematically. In order to conduct the experiment and collect data, we used the BioKin-Mobi sensor setup and it is attached to the club as shown in Figure 4. In this situation, for example, variable $v$ the club head speed, is one of the significant parameters in the golf swing. Three dimensional velocity records will be used in the analysis, especially the velocity magnitude as the club head speed.

BioKin uses ARM Cortex-M3 based microcontrollers for embedded applications featuring a high level of integration and low power consumption. The SD card-version 4 BioKin uses LPC1769 at the operational frequency of $100 \mathrm{MHz}$ and the MPU-9250 is a System in Package (SiP) that combines two chips: the MPU-6500, which contains a 3-axis gyroscope, a 3-axis accelerometer, and an on-board Digital Motion Processor ${ }^{\mathrm{TM}}$ (DMP $^{\mathrm{TM}}$ ) capable of processing complex Motion Fusion algorithms; and the AK8963, the market leading 3-axis digital compass. All real time data stored in the SD card for the entire period of experiment is then retrieved from the card for data analysis. The SD card version 4 of the sensor was proven to have been the better one for the purpose of this experiment as it needed lesser setup time. 


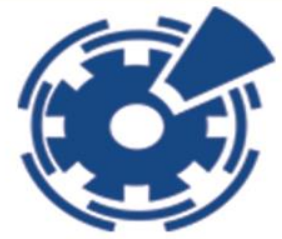

Club head speed of a golf swing is defined as the velocity at which a golf club head impacts with the golf ball during the downswing. However, a golf swing in sand bunkers is different from this notion. In a greenside bunker shot, golf club is not going to hit the ball directly but the club head enters the sand first. The sensor attached to the club head will measure the angular velocity data. We conduct these angular velocity experiments in order to confirm any significant difference between skilled golfers (low handicap) and amateur golfers (high handicap).

Figure 4: BioKin sensor attachment for data capturing

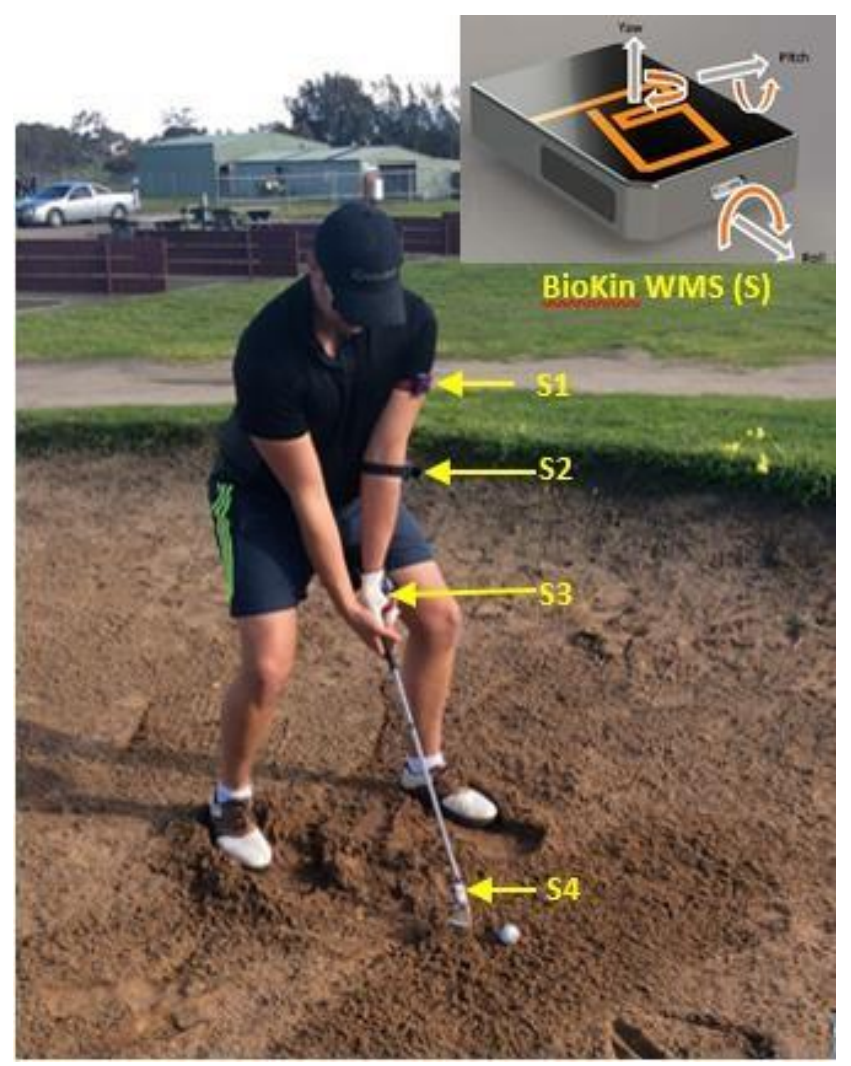

\section{Results}

Herewith, we present some experimental results of club head speed when it comes to sand bunker shots. Several experiments have been conducted in order to show the difference between low handicap golfers and high handicap players. Figure 5 shows a typical velocity profile generated with the swing in sand bunker from a professional golfer whose handicap is one.

Figure 5: Club head velocity of a low handicap (1) in a greenside bunker shot 

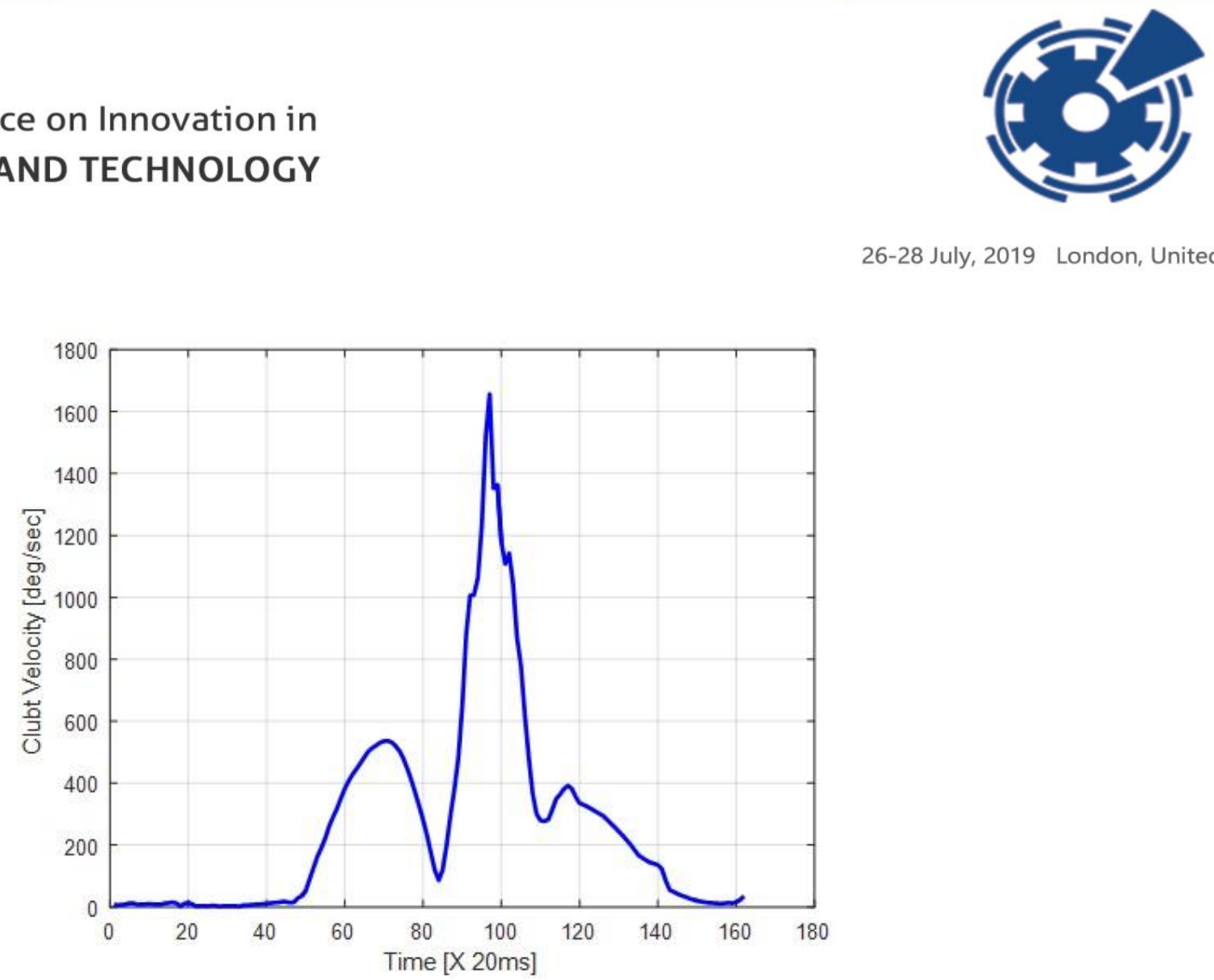

Figure 6 shows the club head velocity of a high handicap (28) in a greenside bunker shot. However, anyone with a handicap above 20 or above is generally considered to have a high golf handicap which means he or she is a beginner. It can be noticed that the peak velocity of the two graphs are different.

Figure 6: Club head velocity of a high handicap (28) in a greenside bunker shot

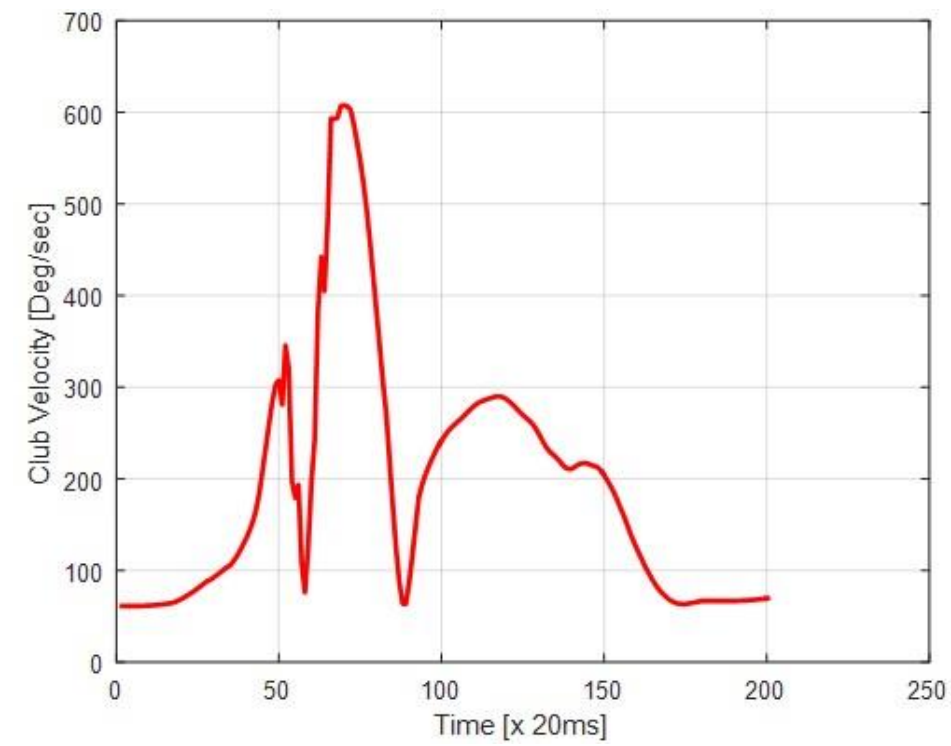

The technique on greenside bunker shots is relatively different from a normal golf shots. The fact is that the ball is not hit first. Rather, the sand behind the ball is impacted first with the aim of bouncing the club through the sand. In Figure 5, damping due to the sand can be seen clearly. In fact, the golf swing by the professional golfer brings it according to the theory whereas it 


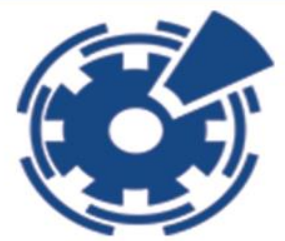

cannot be seen in Figure 6. Figure 7 shows a comparison of three different velocity profiles from three players having different HCs.

Figure 7: Comparison of club head velocity of three different handicaps $(1,6 \& 28)$ in a greenside bunker shot

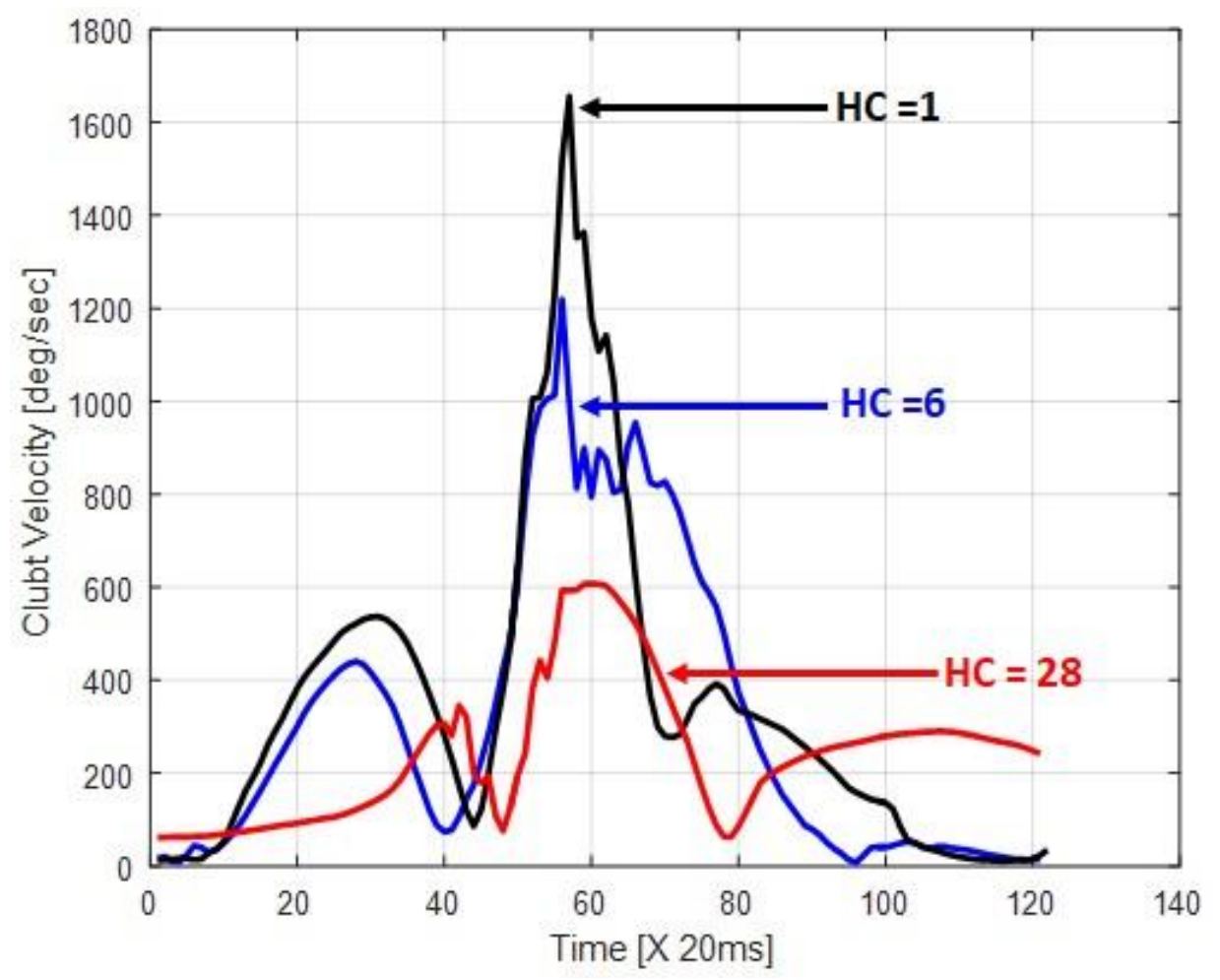

Variation in greenside bunker swing mechanics between golfers of different skill levels can be observed in this graph. Back swing for both handicap 1 and handicap 6 is almost the same. Figure 8 shows few samples of peak velocity of candidate 1 and candidate 2 which are having handicap 1 and handicap 28 respectively. It can be observed that the high handicapper is having high velocity variations in the peaks whereas the low handicapper is having low velocity variations.

Figure 8: Samples of club head velocities for low handicap (1) and high handicap (28). 
$6^{\text {th }}$ International Conference on Innovation in SCIENCE AND TECHNOLOGY

26-28 July, 2019 London, United Kingdom

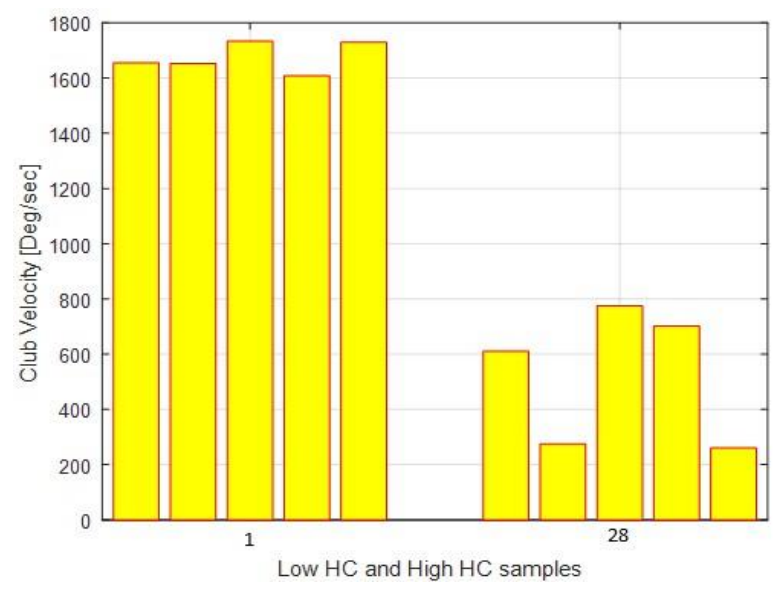

Figure 9 shows club head velocity vs handicap for different player's handicap from 1 to 28 . These samples are selected from large number of greenside bunker shots meeting different practical conditions in real golf. In Figure 9, it can be noticed that velocities associated with handicap 25 have been diverged. If that data set also accounted for the correlation coefficient will be -0.897 .

Figure 9: Club head velocity vs handicap for different players

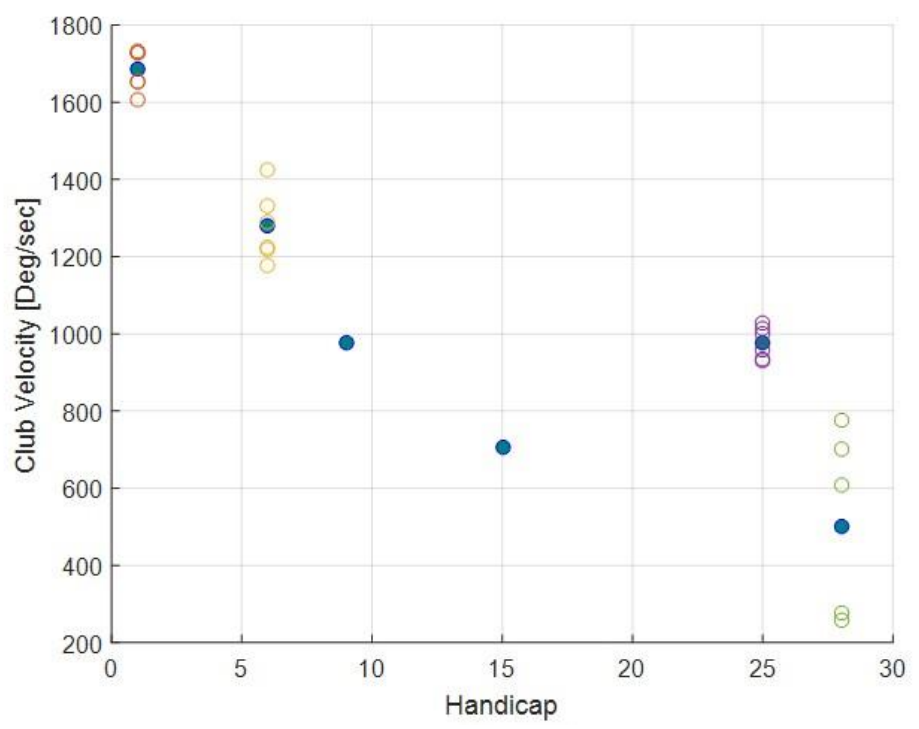




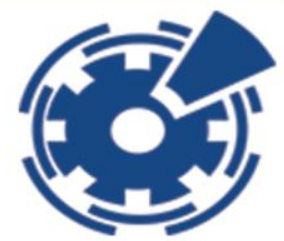

26-28 July, 2019 London, United Kingdom

If we remove that data set, then the correlation coefficient will be -0.946 . In fact, some golfers handicap values are not accurate due to several reasons. Figure 10 shows the pleak club head velocity of the backswing (BS) and downswing together with handicap for different players.

Figure 10: Club head velocity of the back swing (BS) and down swing with handicap for different players

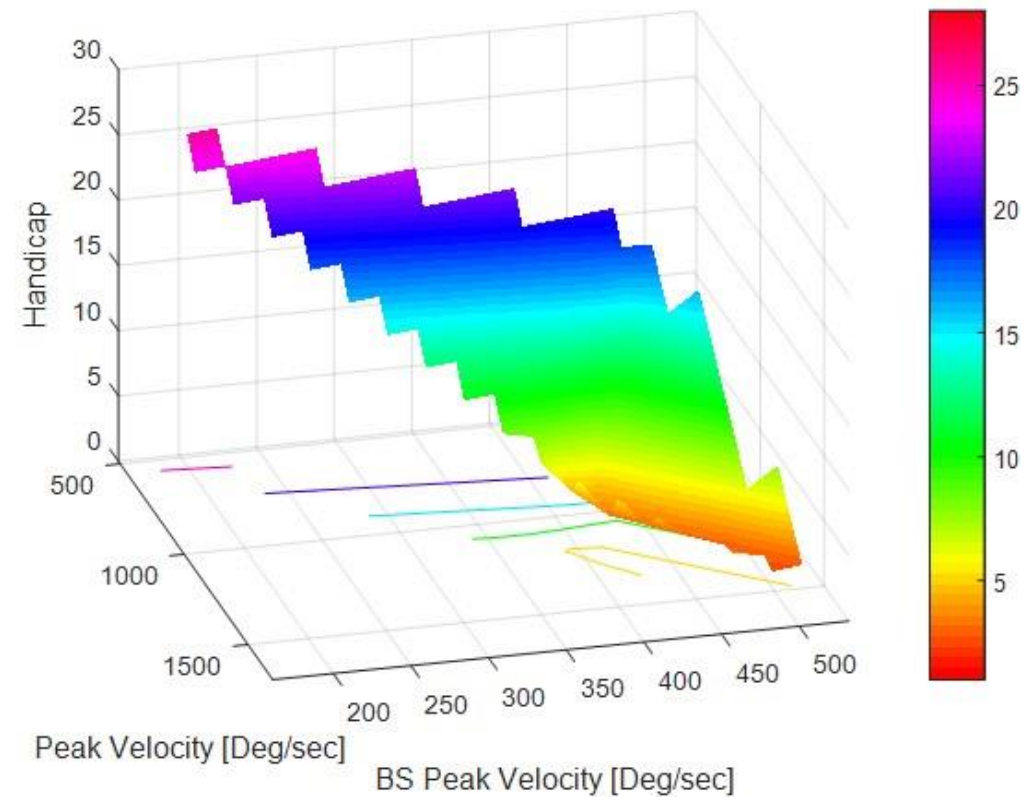

\section{Conclusion}

The first major outcome of this research is the successful implementation of the BioKin sensor setup to observe and capture real time field data that is used to analyse the golf swing pattern at impact between elite and non-elite golfers in the execution of greenside bunker shots. Secondly, experimental results show that data collected by the setup can be effectively used to identify performance enhancement parameters. In this study, we found that elite golfer bunker shot were effective when executed with proper techniques. Two key parameters determined to be of significance were 1) maximum velocity at impact and 2) point of entry into the sand behind the ball for an effective greenside bunker shot. The result showed that for effective greenside bunker shots elite golfer's impact zone was at the bottom of the downswing at maximum velocity and entry into the sand behind the ball. The result also showed that club head velocity at impact was higher for low handicap players in comparison to higher handicaps. Generally, it was found that the lower the handicap the higher the club head velocity which is a key parameter for an effective greenside bunker shot. 


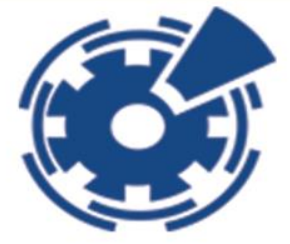

\section{Acknowledgment}

Research group would like to express their genuine appreciations to Tower Links Golf Club, Ras Al Khaimah, UAE and Barwon Valley Golf Club, Melbourne, Australia for using their facilities to obtain the data during the experiment sessions. Moreover, we would like to thank both elite and amateur golfers of the clubs that volunteered to participate in this experiments.

\section{References}

[1] The R\&A and the International Golf Federation. (2018). The truth about Golf, The R\&A St Andrews, Fife, Scotland, 1-18.

[2] Farrally, M. R., Cochran, A. J., Crews, D. J., Hurdzan, M. J., Price, R. J., Snow, J.T. \& Thomas, P.R. (2003). Golf science research at the beginning of the twenty first century, Journal of Sports Sciences, 21:9, 753-765.

[3] European Golf Association Report. (2019). Place de la Croix-Blanche 19 - CP 110 $\mathrm{CH}-1066$ Epalinges, Switzerland.

[4] Betzler, N., Monk, S., Wallace, E., Otto, S. R. \& Shan, G. (2008). From the double pendulum model to full-body simulation: Evolution of golf swing modelling, Sports Technology, 1:45, 175-188.

[5] Brown, S. J., Nevill, A. M., Monk, S. A., Otto, S. R. \& Scott, W. (2011). Determination of the swing technique characteristics and performance outcome relationship in golf driving for low handicap female golfers, Journal of Sports Sciences, 29:14, 1483-1491.

[6] Bradshaw, E. J., Keogh, J. W. L., Hume, P. A., Maulder, P. S., Nortje, J. \& Marnewick, M.

(2009). The effect of biological movement variability on the performance of the golf swing in high- and low-handicapped players. Research Quarterly for Exercise and Sport, 80, 185196.

[7] Smith, D. Wright, C. J. \& Cantwell, C. (2008). Beating the Bunker: The effect of PETTLEP imagery on golf bunker shot performance, Journal of Research Quarterly for Exercise and Sport, 79:3, 385-391.

[8] Wang, J. J., Yang, P. F., Ho, W. H. \& Shiang, T. Y. (2015). Determine an effective golf swing by swing speed and impact precision tests, Journal of Sports Science, 4, 244-249. 


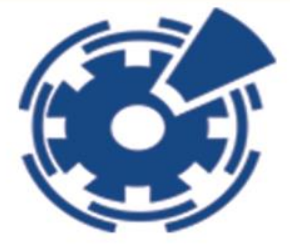

[9] Grober, R. D. (2010). Measuring Tempo, Rhythm, Timing and the Torques that Generate Power in Golf Swing, Department of Applied Physics, Yale University, New Haven, CT, 06520.

[10] Fradkin, A. J. Sherman, C. A. and Finch, C. (2005). How well does club head speed correlate with golf handicaps, Journal of science and medicine in sport, Sports Medicine Australia, 7: 4, 465-472.

[11] Joyce, C. (2016). An examination of the correlation amongst trunk flexibility, $x-$ factor and club head speed in skilled golfers', Journal of Sports Sciences.

[12] Choi, A., Lee, I. K., Choi, M. T. and Mun, J. H. (2016). Interjoint coordination between hips and trunk during downswings: Effects on the club head speed, Journal of Sports Sciences, 34, 1991-1997. 